\title{
Energy efficiency of external walls of buildings with aggressive production environments
}

\author{
Irina Sokolova ${ }^{1, *}$ \\ ${ }^{1}$ Moscow State University of Civil Engineering Yaroslavskoe shosse, 26, 129337, Moscow, Russia
}

\begin{abstract}
Much attention is paid now to the energy efficiency of external enclosing structures. The study of this issue is especially important for external walls, operating in an aggressive environment. The author proposed the light polymer-silicate shungizit concrete (LPSC) for exterior walls of buildings with acidic, wet-gas environments. Shungizite as a lightweight aggregate was chosen because of its high acid resistance. The experience of using shungizit concrete on cement binder for structures of residential, public and industrial buildings was olso taken into account. Previously, the author conducted studies on the physic-mechanical properties of LPSC with a density of $1000-1200 \mathrm{~kg} / \mathrm{m} 3$. Studies have shown that this material can be applied to the exterior walls of buildings with acidic, wet-gas environments. This article presents the results of studies on the energy efficiency of walls made of LPSC.
\end{abstract}

\section{Introduction}

The external walls of industrial buildings with aggressive production environments are usually made of concrete on cement binder. Wall surfaces are covered with protective coatings The service life of coatings is less than the service life of the wall material. Periodic recovery of coatings requires additional costs [1,2]. Polymersilicate concrete is successfully applied to structures of buildings with an acidic corrosive environment [3]. Prefabricated and monolithic structures are made of this material, working under conditions of exposure to an acidic aggressive environment: floor coverings, technical equipment lining, tanks for electrolysis processes. The light polymer-silicate shungizit concrete (LPSC) was proposed by the author for the exterior walls of buildings with an acidic, wetgas production environment. The components of concrete on the basis of shungite and shungizite were chosen because of their high acid resistance [4]. The experience has been gained of using shungizit concrete on cement binder in civil engineering and in industrial buildings without aggressive influence of the production environment. Small shungite and shungizite fractions are waste of shungizite gravel production. The use of these components will have a positive impact on the environment. Walls of this material do not need additional protection of their surface.

LPSC compositions were selected and their physical and mechanical properties were studied. The sorption moisture of the material has also been studied. The results of these studies are presented in the articles $[4,5]$. Thermal conductivity of structural heat-insulating

* Corresponding author: i.socolova@yandex.ru 
LPSC. with a density of $1000-1200 \mathrm{~kg} / \mathrm{m} 3$ has not been previously studied. The results of the study of thermal conductivity of the proposed material for exterior walls are given in this article.

\section{The object of the study}

The object of the study is the thermal conductivity of LPSC compositions, proposed by the author. The compositions differed in the size of the large schungizite aggregate fractions. Shungite and shungizite fine fractions were used. The compositions also differed in the consumption of liquid glass, sodium fluorosilicate, and furyl alcohol. The consumption of components for the compositions adopted for the study of thermal conductivity is presented in Table 1.

Table 1. The consumption of components for compositions adopted for the study.

\begin{tabular}{|l|l|l|l|}
\hline \multirow{2}{*}{ Components } & \multicolumn{3}{|l|}{ Consumption of components, $\mathrm{kg} / \mathrm{l}$} \\
\cline { 2 - 4 } & 1 & 2 & 3 \\
\hline Shungizite gravel & - & - & $465 / 950$ \\
fraction 5-10 & $304 / 950$ & $304 / 950$ & - \\
fraction 10-20 & $187 / 155$ & $187 / 155$ & $187 / 155$ \\
Shungizite sand & $184 / 265$ & $184 / 265$ & $184 / 265$ \\
fraction 0,15-2,5 & & & \\
fraction 0,15-5,0 & $190 / 220$ & - & $190 / 220$ \\
Shungizite fine grinding fraction & - & $268 / 220$ & - \\
Shungite fine grinding fraction & & $265 / 186$ & $300 / 218$ \\
Glass liquid density of 1.38 & $284 / 205$ & $8,0 / 7,1$ & $9,0 / 8,0$ \\
Furyl alcohol & $8,5 / 7,6$ & $38,0 / 37,1$ & $45,0 / 43,9$ \\
Sodium fluorosilicate & $42,5 / 41,5$ & $1245 / 1820$ & $1380 / 1900$ \\
Total consumption & $1200 / 1845$ & 1245 & \\
\hline
\end{tabular}

The thermal conductivity coefficient was studied as a property of the material, which determines its energy efficiency The thermal conductivity coefficient depends on the density of the material and its humidity. The thermal conductivity of light materials is not great. This property is mainly due to the presence of pores filled with air in their structure. Water is a better conductor of heat than air. The presence of water in the pores increases the thermal conductivity of concrete. The thermal conductivity coefficient of the LPSC was determined by the standard method. The essence of the method lies in the fact that a heat flow is created through a flat sample of a certain thickness. A heat flow was directed perpendicular to the front surfaces of the sample. The measurement of the density of the heat flow through the sample and the temperature on its face surfaces was carried out after the establishment of a stationary thermal regime. The amount of thermal conductivity was calculated from the measurement results. The samples had the form of a plate with a size of 250x250 mm and a thickness of $45-50 \mathrm{~mm}$, flat, smooth and parallel surfaces. The thickness of the samples was measured with a calipers with an error of up to $0.1 \mathrm{~mm}$ in four places around the perimeter and was calculated as the arithmetic average of the results of all measurements. The arithmetic average of the results of measurements of three samples was taken as the result of the determination of thermal conductivity. The resulting value of heat conduction was related to the test temperature calculated by the formula: 


$$
t=\frac{\mathrm{t} 1-\mathrm{t} 2}{2}
$$

Where:

$\mathrm{t}_{1}$ - sample top surface temperature, ${ }^{\circ} \mathrm{C}$,

$\mathrm{t}_{2}$ - sample bottom temperature, ${ }^{\circ} \mathrm{C}$,

$\mathrm{t}$ - test temperature, ${ }^{\circ} \mathrm{C}$.

The thermal conductivity coefficient the coefficient was calculated by the formula:

$$
\lambda=\frac{q-\delta}{\mathrm{t} 1-\mathrm{t} 2}
$$

where $\mathrm{q}$ - heat flux density through the sample, $\mathrm{W} / \mathrm{m} 2$;

$\delta$ - the thickness of the sample,m;

t1 and $\mathrm{t} 2$ - the same as in formula $1,{ }^{\circ} \mathrm{C}$.

Mathematical processing of research results was carried out by the least square method. Analysis of the results showed a linear dependence of the coefficient of thermal conductivity on the density of LPSC in the dry state (when it changes from 900 to 1200 $\mathrm{kg} / \mathrm{m} 3$ ). This dependence can be expressed by the equation

$$
\lambda_{\mathrm{o}}=0.000313 \rho_{\mathrm{o}}-0.055, \mathrm{~W} / \mathrm{m} \cdot{ }^{\circ} \mathrm{C}
$$

where $\rho_{\circ}$ - the density of concrete in dry condition, $\mathrm{kg} / \mathrm{m} 3$;

0,000313 - the angular coefficient of the equation of a line;

0,055 - initial ordinate of the equation of a line;

$\lambda_{\circ}$ - thermal conductivity coefficient LPSC in the dry state, $\mathrm{W} / \mathrm{m}{ }^{\circ} \mathrm{C}$.

The dependence of thermal conductivity on moisture content within the sorption moisture of concrete can also be taken linear and is expressed by the equation

$$
\lambda \mathrm{wm}=\mathrm{KWm}+\lambda_{\mathrm{o}}
$$

where $\mathrm{Wm}$ - sorption moisture of concrete in a dry state; \%;

$\mathrm{K}$ - angular coefficient of the equation of the line is equal to 0.009 ;

$\lambda_{\circ}$ - coefficient of thermal conductivity of concrete in dry state, determined from the equation (3) ;

$\lambda \mathrm{wm}$ - coefficient of thermal conductivity of concrete with moisture $\mathrm{Wm} ., \mathrm{W} / \mathrm{m}{ }^{\circ} \mathrm{C}$

The maximum sorption moisture of the LPSC can be adopted for compositions 1, 2, 3 respectively, 10, 8, 9\%, according to the data of the performed experiments [5].

\section{Results}

The results of studies of thermal conductivity of LPSC are presented in table 2 .

Table 2. The thermal conductivity coefficient of LPSC.in absolutely dry condition and at maximum sorption humidity.

\begin{tabular}{|l|l|l|l|l|}
\hline \multirow{2}{*}{ № } & & \multicolumn{3}{|c|}{ Characteristics } \\
\cline { 3 - 5 } & \multirow{2}{*}{$\begin{array}{l}\text { Density, } \\
\mathrm{kg} / \mathrm{m} 3\end{array}$} & $\begin{array}{l}\text { Coefficient of } \\
\text { thermal conductivity, } \mathrm{W} /{ }^{\circ} \mathrm{C}\end{array}$ \\
\cline { 3 - 5 } & & $\begin{array}{l}\text { in absolutely dry } \\
\text { condition } \lambda_{\circ}, \mathrm{W} / \mathrm{m}{ }^{\circ} \mathrm{C}\end{array}$ & $\begin{array}{l}\text { at maximum sorption } \\
\text { humidity } \lambda, \mathrm{W} / \mathrm{m}^{\circ} \mathrm{C}\end{array}$ \\
\hline 1. & $\begin{array}{l}\text { LPSC.with shungizite } \\
\text { fine aggregate }\end{array}$ & 1000 & 0,26 & 0,35 \\
\hline 2. & $\begin{array}{l}\text { LPSC. with shungite fine } \\
\text { aggregate }\end{array}$ & 1100 & 0,32 & 0,38 \\
\hline 3. & $\begin{array}{l}\text { LPSC.on shungizite fine } \\
\text { aggregate }\end{array}$ & 1200 & 0,35 & 0,41 \\
\hline
\end{tabular}


The dependence of thermal conductivity on the density of LPSC in a dry state is shown in Figure 1and the dependence of the thermal conductivity of the material on moisture is shown in Figure 2.

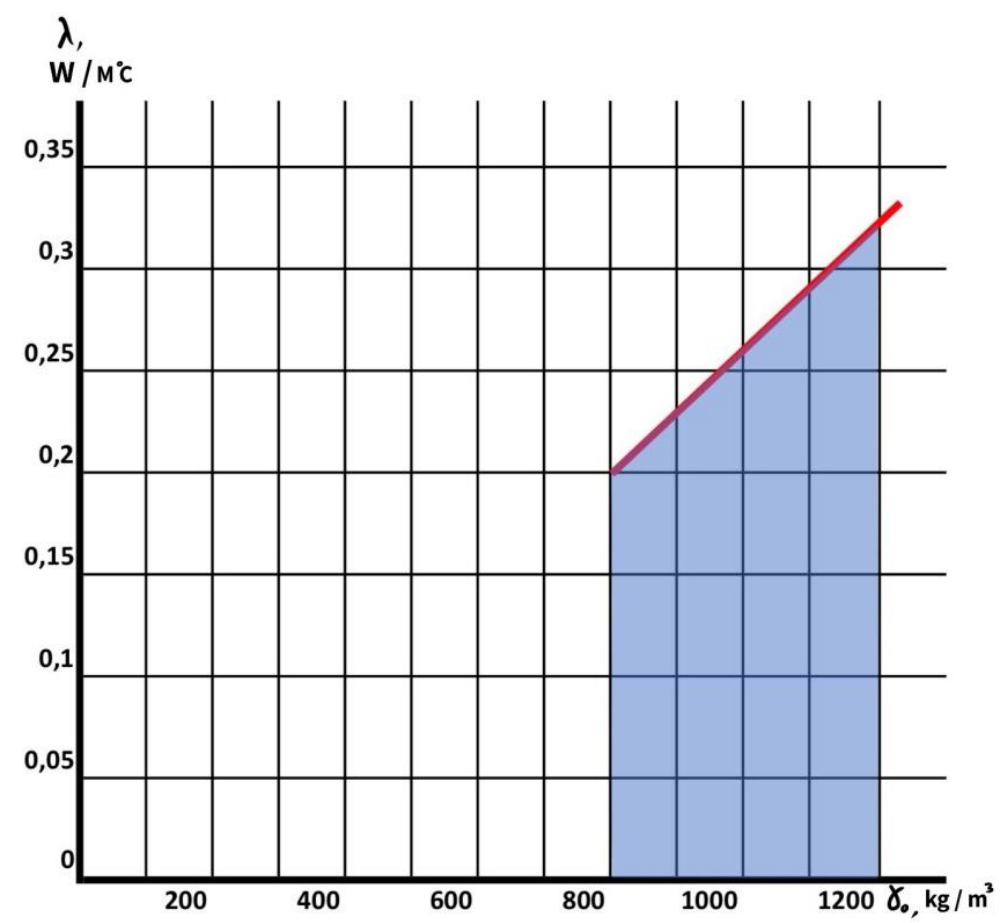

Fig. 1. The dependence of thermal conductivity on the density of LPSC in a dry state.

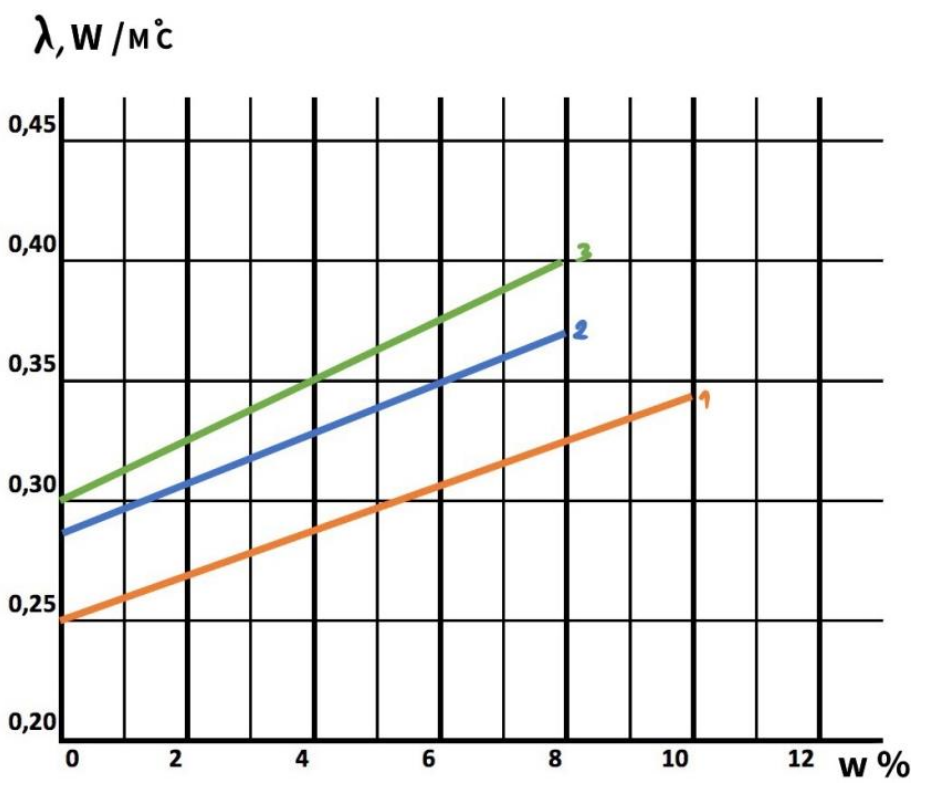

Fig. 2. The dependence of thermal conductivity of the material on moisture, where: 1 - LPSC with shungizite fine aggregate, $\gamma_{0}=1000 \mathrm{~kg} / \mathrm{m} 3 ; 2-$ LPSC with shungite fine aggregate, $\gamma_{0}=1100 \mathrm{~kg} / \mathrm{m} 3$ ; 3 - LPSC on shungizite fine aggregate, $\gamma_{0}=1200 \mathrm{~kg} / \mathrm{m} 3$. 


\section{Conclusions}

The results of thermal conductivity research showed the prospects of light polymer silicate schungizit concrete as the material of exterior walls from the point of view of its energy efficiency. It is concluded that the creation of external walls without additional protection is possible if the material proposed by the author is used. The material can be recommended for exterior walls envelopes with aggressive wet gas production environment.

\section{References}

1. I.L. Pavlova, A.K. Igol'nikov, Tekhnicheskoe regulirovanie v transportnom stroitel'stve 1(15), 6-9 (2016)

2. N.K. Rozental', V.F. Stepanova, G.V. Chekhij, Beton i ZHelezobeton - vzglyad v budushchee (NIU MGSU, Moscow, 2014)

3. O. Mosin, I. Ignatova, Nanoindustriya 3, 41 (2013)

4. I.V. Sokolova, Izvestiya vysshih uchebnyh zavedenij. Tekhnologiya tekstil'noj promyshlennosti 4(370), 258-262 (2017)

5. I.V. Sokolova, Inzhenernyj vestnik Dona, Rostov-na-Donu, Yuzhnyj federal'nyj universitet 1(48), 173 (2018) 